\title{
Heterogeneous catalytic reaction of glycerol with acetone for solketal production
}

\author{
Hary Sulistyo ${ }^{1, *}$, Indri Hapsari ${ }^{1}$, Budhijanto ${ }^{1}$, Wahyudi Budi Sediawan ${ }^{1}$, Suprihastuti Sri Rahayu ${ }^{1}$ and Muhammad Mufti \\ Azis $^{1}$
}

${ }^{1}$ Department of Chemical Engineering, Faculty of Engineering, Gadjah Mada University, Jln Grafika No 2, Yogyakarta 55281, Indonesia

\begin{abstract}
The rapid growth of biodiesel industries has also increased the production of glycerol as side product. Without proper treatment, glycerol may cause serious problem for the environment. Glycerol can be reacted with acetone to produce solketal as a fuel additive. The aim of this research was to study the glycerol ketalization with acetone using Amberlyst-15 as catalyst. Experiments were undertaken in a batch reactor. A set of experiment was conducted at varying temperature $\left(35\right.$ to $\left.60^{\circ} \mathrm{C}\right)$, initial mole ratio of acetone to glycerol $(2-6)$ and catalyst loading $(1,3,5$ and $7 \%$ w/w). Sample was analyzed every 30 minutes. The results showed that optimal condition was achieved at temperature of $60{ }^{\circ} \mathrm{C}$, initial mole ratio of acetone to glycerol of 3, and the catalyst load of 3\%. The highest glycerol conversion achieved was $87.41 \%$ at $60^{\circ} \mathrm{C}$ for 3 hours reaction. The Pseudo Steady State Hypothesis (PSSH) has been developed as $r_{n e t}=\frac{k_{4} \cdot C_{G} \cdot C_{A c}}{1+k_{5} \cdot C_{G}}$. Parameter estimation of $\mathrm{k}_{4}$ and $\mathrm{k}_{5}$ were evaluated from experimental data at various temperatures. It appears that the model predicted the experimental data well at high conversion (above $80 \mathrm{~min}$ ) and showed relatively poor prediction below $80 \mathrm{~min}$.
\end{abstract}

\section{Introduction}

Glycerol is known as a byproduct from biodiesel production. As a result of the increasing biodiesel production, there has been a surplus of glycerol supply. Utilization of glycerol to produce oxygenated compounds such as acetal and ketals is a potential pathway for glycerol conversion. Solketal is one of the chemical compound which can be synthesized from glycerol by acetalization with acetone. Solketal can be used as fuel additives to improve the octane number and cold flow properties, reduce particulate emission and gum formation [1]. As a fuel additive, it is common to blend solketal at 3, 5, 7 and $10 \mathrm{vol} \%$ with oxygenate free gasoline. When compared to unblended gasoline, the higher value of octane number is obtained with blended ones [2]. Meanwhile Dmitriev et al. [3] mentioned that gasoline with solketal as oxygenated have improved detergent properties, combustion characteristic and form smaller amount of $\mathrm{CO}$ and hydrocarbons during combustion.

For solketal production, some researchers have used solid catalyst due to better separation aspect and reusability of solid catalyst. Reddy et al. [4] investigated ketalization of glycerol using promoted zirconia catalyst and exhibited promising catalytic activity. When Amberlyst-46 as catalyst load was increased from $0.5 \%$ to $1.00 \%$, solketal yields increased significantly from $59 \%$ to $84 \%$ [2]. Mallesham et al. [5] found that among the solid catalyst, the Amberlyst-15 acid resin catalyst exhibited the highest glycerol conversion within 0.25 hour of reaction time. Manjunathan et al. [6] has

\footnotetext{
*Corresponding author: hary@ugm.ac.id
}

investigated the use of modified zeolite beta catalysts of $5 \mathrm{wt} \%$ to obtain the glycerol conversion of $87.5 \%$.

In order to study the kinetics of glycerol ketalization using zeolite H-BEA as catalyst, Rosa et al. [7] expressed the kinetics in the pseudo homogeneous model such as reversible kinetics model. The equilibrium constant for a range of temperature $40-80^{\circ} \mathrm{C}$ the forward and reverse reaction energy activity were similar. The impacts of temperature on the reaction rate, conversion and selectivity were discussed. It was shown that the solketal yields was reduced when the temperature was increased. When temperature is too high, acetone is prone to vaporization while the glycerol is in the liquid phase on the surface of active catalyst [8,9]. In addition, Samoilov et al. [10] expressed the elevation of the temperature led to a decrease in selectivity for solketal formation. Esteban et al. [11] expressed the temperature higher than $313 \mathrm{~K}$ was required to facilitate removal of water for shifting the reaction equilibrium to the product.

Agirre et al. [12] investigated ketalization glycerol with formaldehyde from 1:1 to 1:3 using amberlyst-47 catalyst. By increasing the molar ratio of glycerol, the equilibrium conversion of the formaldehyde increased as well. As the acetone to glycerol molar ratio increased from $4: 1$ to $8: 1$, glycerol conversion was found to increase from $52 \%$ to $100 \%$ associated with decreasing the selectivity to solketal and increasing that of 6-acetal [13]. Manjunathan et al. [6] mentioned that glycerol conversion increased with the increase of acetone to glycerol molar ratio from $1: 1$ to $3: 1$. It was found that the acetone to glycerol molar ratio of $2: 1$ appeared to be the optimum condition. The aim of present work was to 
undertake the Pseudo Steady State Hypothesis (PSSH) model of solketal synthesize from glycerol and acetone using Amberlyst 15 as catalyst. For that purpose, glycerol conversion was evaluated by varying systematically, temperature, catalyst loading and acetone to glycerol ratios.

\section{Materials and methods}

\subsection{Material}

The reactants were glycerol and acetone. Glycerol technical grade was used with further purification. Acetone $99 \mathrm{wt} \%$ purity were purchased from Merck. The catalyst used in the study was Amberlyst -15 which was purchased from Sigma Aldrich.

\subsection{Experimental method}

The synthesis of solketal was conducted in a three neck flask reactor with round bottom and equipped with stirrer, heater, condenser, thermometer and sampling apparatus. Glycerol was filled into the reactor, then stirred and heated to attain the required temperature. Subsequently, acetone as reactant and Amberlyst 15 as the catalyst were added to the reactor. Samplings were conducted every 30 minutes which was followed by separation of catalyst by filtration. The samples were analyzed using periodic acid.

\subsection{Modelling method}

The reaction rate mechanism for the ketalization reaction between glycerol and acetone has been proposed by Trifoi et al. [1] and Mallesham et al. [5]. The reaction mechanism can be expressed as follow:

$$
G+A c \leftrightarrow H \leftrightarrow S+W
$$

$\mathrm{H}$ is hemiacetals which is known as the intermediate. Assuming that the intermediate product of $\mathrm{H}$ was formed and disappeared spontaneously, one may simplify the reaction mechanism as follow:

$$
\begin{gathered}
G+{ }^{*} \leftrightarrow G^{*} \\
G^{*}+A c \rightarrow S+W+*
\end{gathered}
$$

From site balance, we may infer that:

$$
C_{G^{*}}+C_{v}=C_{t o t}
$$

By assuming equilibrium in Eq. 1, we obtain:

$$
\begin{gathered}
0=k_{1} \cdot C_{G} \cdot C_{v}-k_{2} \cdot C_{G^{*}} \\
0=k_{1} \cdot C_{G} \cdot\left(C_{t o t}-C_{G^{*}}\right)-k_{2} \cdot C_{G^{*}} \\
C_{G^{*}}=\frac{k_{1} \cdot C_{G} \cdot C_{t o t}}{k_{2}+k_{1} \cdot C_{G}} \\
r_{n e t}=k_{3} \cdot C_{G^{*}} \cdot C_{A c} \\
r_{n e t}=k_{3} \cdot \frac{k_{1} \cdot C_{G} \cdot C_{t o t}}{k_{2}+k_{1} \cdot C_{G}} \cdot C_{A c}
\end{gathered}
$$

The concentration of acetone is typically in excess compared to the glycerol. Thus, the change of acetone concentration followed stoichiometric relationship with the amount of glycerol converted. As a result, by using Pseudo Steady State Hypothesis (PSSH) model, the reaction rate can be modified as follow:

$$
\begin{gathered}
r_{n e t}=\frac{k_{4} \cdot C_{G} \cdot C_{A c}}{1+k_{5} \cdot C_{G}} \\
k_{4}=A_{4} \cdot \exp \left(\frac{-E a_{4}}{R \cdot T(K)}\right) \\
k_{5}=A_{5} \cdot \exp \left(\frac{-E a_{5}}{R \cdot T(K)}\right)
\end{gathered}
$$

The reaction rate as in Eq. 5 was evaluated with the batch reactor data. Parameter k4 and k5 were assumed to follow Arrhenius equations as shown in Eqs. 6 and 7. Hence, there are 4 parameters to fit namely: preexponential factor (A) and activation energy (Ea) as described in Eqs. 6 and 7.

The batch reactor was modeled as:

$$
-r_{n e t} \cdot W=V \frac{d C_{G}}{d t}
$$

All parameters were estimated to the experimental data from temperature variation. Gradient search methods as well as ODE solver in MATLAB have been used for parameter fitting and simulation, respectively. The objective function was to minimize the SSE from residuals of glycerol concentration from simulation and experimental data.

For simulation, the initial concentration of acetone and glycerol used were $10.8 \mathrm{M}$ and $2.7 \mathrm{M}$, respectively. The liquid volume (V) was kept constant at $370 \mathrm{ml}$. Similarly, the weight of catalyst was maintained at 2.76 gr which corresponds to 3 wt. \% of catalyst.

\section{Results and discussion}

Solketal synthesis from glycerol with acetone over Amberlyst 15 catalyst was investigated. In order to attain the optimum reaction condition, temperature, catalyst loading, acetone to glycerol molar ratio were studied. The time of reaction and stirrer speed were fixed at 3 hours and $500 \mathrm{rpm}$, respectively. The stirrer speed has been set constant at $500 \mathrm{rpm}$. Nanda et al. [[8] carried out the experiments of solketal synthesis from glycerol with acetone under stirring speed 400 and $1100 \mathrm{rpm}$ and there was negligible influence of stirrer speed on the reaction time and glycerol conversion. The same conclusion was reached by Agirre et al. [14] when reacting glycerol with acetaldehyde at 700 to $1250 \mathrm{rpm}$ and aldehyde to glycerol molar ratio of $3: 1$.

\subsection{The effect of reaction temperature}

The effect of the reaction temperature on ketalization of glycerol with acetone was presented in Fig 1. As shown in Fig 1, the highest glycerol conversion was attained as high as $82.26 \%$ at $60^{\circ} \mathrm{C}$. The same result was also reported by Ilgen et al. [2] which showed the glycerol 
conversion of $84 \%$ was attained at $60^{\circ} \mathrm{C}$. Generally, one may infer that the glycerol conversion decreases with the increase of temperature. It was probably caused by vaporization of acetone when approaching the acetone boiling point [10]. When the temperature increased, acetone would vaporize and more acetone would present in the gas phase while the glycerol is in the liquid phase on the surface of the catalyst $[\mathbf{1}, \mathbf{8}, \mathbf{9}]$. The synthesis of solketal using $\mathrm{Ni}-\mathrm{Zr}$ supported on activated carbon catalyst has been reported by Khayoom and Hameed [12] and they found that $45^{\circ} \mathrm{C}$ was the best temperature. At $45^{\circ} \mathrm{C}$, complete glycerol conversion was obtained with selectivity of $74 \%$.

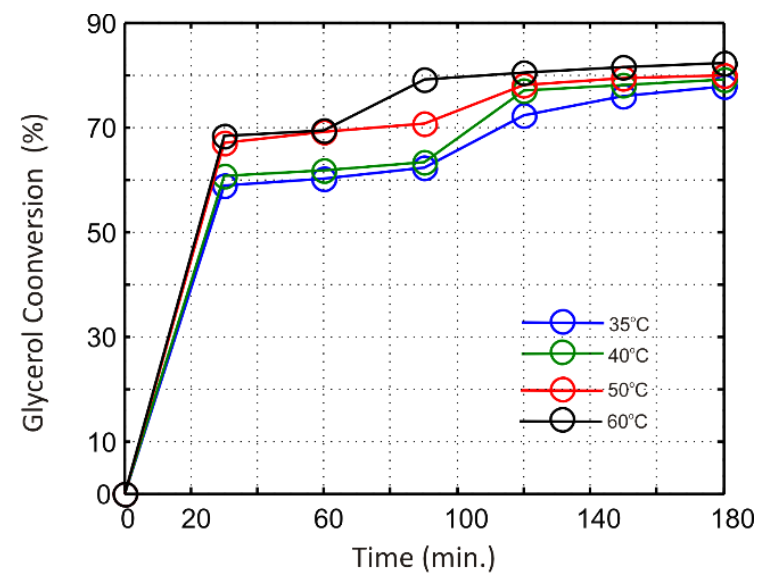

Figure 1. The effect of reaction temperatures to the glycerol conversion

\subsection{The effect of catalyst loading}

The effect of catalyst loading to glycerol conversion has also been conducted by varying the loading of Amberlyst 15 from 1, 3, 5 and $7 \mathrm{wt} \%$ to glycerol weight. For this variation, acetone to glycerol ratio of $3: 1$ and temperature of $60^{\circ} \mathrm{C}$ were maintained. Fig. 2 displayed the glycerol conversion by varying catalyst loading. As shown in Fig 2, the glycerol conversion was increased from 69.16 to $74.15 \%$ with the increase of catalyst loading. It can be concluded that no influence of catalyst loading on reaction rate lead to glycerol conversion. When catalyst loading increase to $7 \%$, the glycerol conversion decrease to $70.40 \%$. This might be due to deposition of catalyst which settle down on the bottom of reactor. By using H-ßeta-1 as catalyst for glycerolysis with acetone, Manjunathan et al. [6] found that the maximum glycerol conversion of $87.10 \%$ for $7.5 \mathrm{wt} \%$ of catalyst amount. Meanwhile, Reddy et al. [4] investigated acetalysation reaction by using zirconia and promoted zirconia as catalyst by varying the catalyst loading from 1 to $5 \mathrm{wt} \%$. The promoted zirconia catalyst exhibited higher catalytic glycerol conversion. The glycerol conversion over zirconia and promoted zirconia catalyst were 10 and $98 \%$, respectively. As the catalyst amount increased from 0.15 to $0.20 \mathrm{~g}$, glycerol conversion reached $100 \%$ and selectivity to 6 -acetal was raised from 16 to $26 \%$ [12].

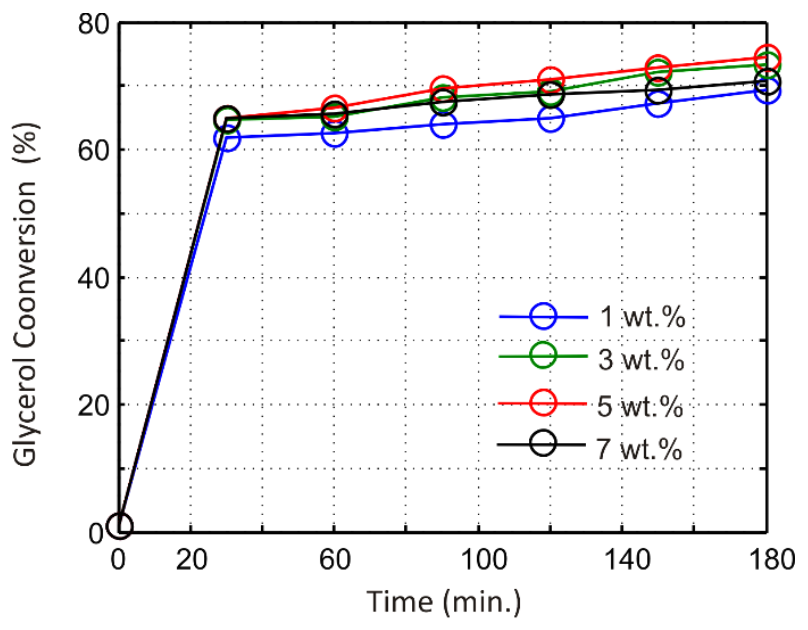

Figure 2. The effect of catalyst loading to the glycerol conversion

\subsection{The effect of acetone to glycerol molar ratio}

In order to study the influence of acetone to glycerol ratio, we have set the catalyst loading of $3 \%$ Amberlyst 15 and temperature of $60^{\circ} \mathrm{C}$. The following investigations were aimed to evaluate the optimum acetone to glycerol molar ratio. Fig. 3 presents the results of glycerol conversion obtained using several acetone to glycerol molar ratio. As the increase of acetone to glycerol molar ratio would cause the increase of glycerol conversion. Increasing the molar ratio of acetone to glycerol from 2 to 6 gave an increase of conversion from 43.92 to $87.41 \%$. An excess of acetone employed in this reaction would drive the forward reaction and enhanced the complete conversion of glycerol. As shown here, the ratio of 3:1 gave the glycerol conversion of $73.15 \%$. Increasing the molar ratio to 4,5 and 6 gave the glycerol conversion of $82.26 \%$, $85.80 \%$ and $87.41 \%$, respectively. It could be concluded that the molar ratio of $3: 1$ was the optimum condition.

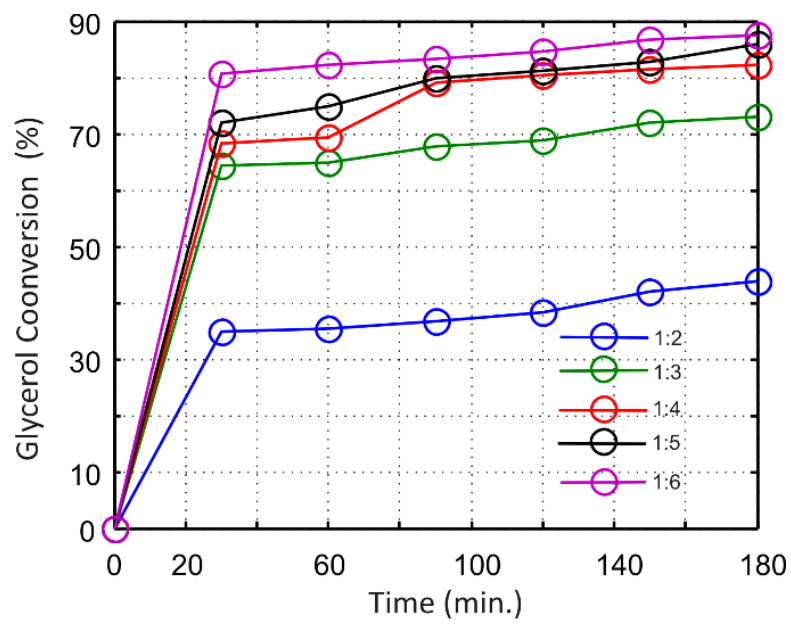

Figure 3. The effect of glycerol to acetone molar ratio to the glycerol conversion

By using promoted zirconia catalyst on acetalisation of glycerol Reddy at al. [4] found the glycerol conversion increased from $62 \%$ to $98 \%$ at molar ratio of $1: 1$ to $6: 1$. If the catalyst was used without promoted zirconia or 
zirconia only the glycerol conversion attained was less than $10 \%$. da Silva et al. [14] undertaken acetilation in the presence of $\mathrm{SnF}_{2}$ catalyst, an increase the molar ratio of acetone to glycerol resulted higher glycerol conversion which range from 58 to $97 \%$. The mass balance showed that the glycerol was converted to solketal. Manjunathan et al. [6] used variation of molar ratio from 1 to 3 and it was found that acetone to glycerol molar ratio of 2:1 turned out to be the optimum for the catalytic transformation of glycerol to solketal. The glycerol conversion remained almost the same with further increase in mole ratio to $3: 1$. Some researchers $[\mathbf{4 , 6}, \mathbf{1 5}]$ observed as the acetone to glycerol molar ratio increase, the glycerol conversion also increase. In addition, it is worth noting that the increase in molar ratio of acetone to glycerol does not influence the selectivity to solketal and remained almost the same that greater than $90 \%$.

\subsection{Kinetic modelling result}

A kinetic model based on PSSH mechanism has been proposed as in Eqs. 1 - 7 with reactor model as in Eq. 8. Comparison between the simulation and experimental results is presented in Fig. 4. It should be mentioned here that the simulation was only based on the effect of temperature as it was found that the glycerol conversion was sensitive to the temperature variation. The model parameters of $\mathrm{A}_{4}, \mathrm{~A}_{5}, \mathrm{Ea}_{4}$ and $\mathrm{Ea}_{5}$ were estimated at various temperatures. From parameter estimation, preexponential factor of $0.04 \mathrm{~L}^{2} \cdot \mathrm{mol}^{-1} \cdot \mathrm{kg}^{-1} \cdot \mathrm{min}^{-1}$ and 0.81 were obtained for $\mathrm{A}_{4}$ and $\mathrm{A}_{5}$, respectively. The activation energy of $15.3 \mathrm{~kJ} / \mathrm{mol}$ and $26.8 \mathrm{~kJ} / \mathrm{mol}$ were obtained for $\mathrm{Ea}_{4}$ and $\mathrm{Ea}_{5}$, respectively. Parameter estimation based on gradient search method also obtained the SSE of 49.04 .

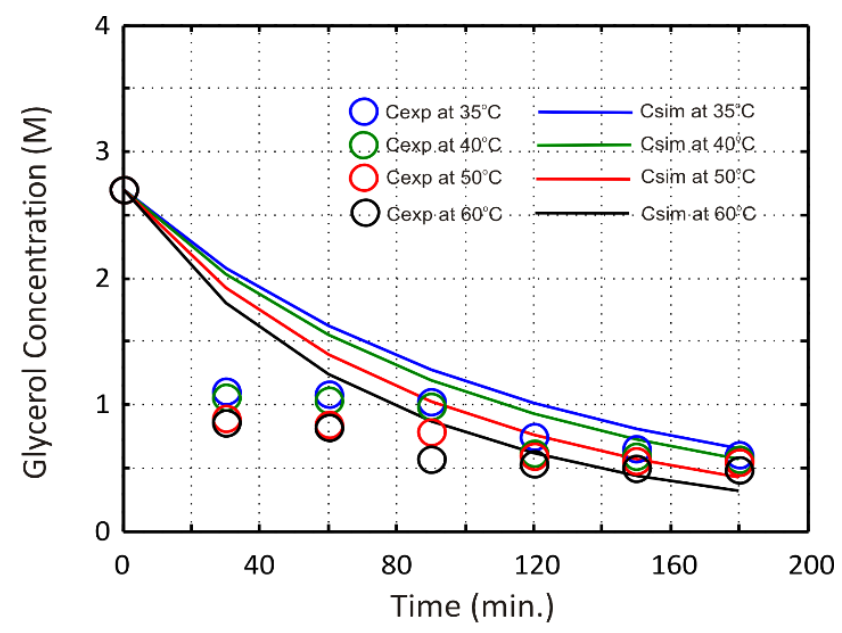

Figure 4. Comparison of glycerol concentration between simulation and experimental data for various temperatures.

It appears that the model predicted the experimental data well at high conversion (above $80 \mathrm{~min}$ ) and showed relatively poor prediction below $80 \mathrm{~min}$. The poor prediction below $80 \mathrm{~min}$ might also indicate that more experimental data is needed to allow the model to capture better the rapid reaction that occurred in the beginning of reaction. However, with present technique, collecting data under $30 \mathrm{~min}$ could be challenging and hence required more advanced analytical technique.

\section{Conclusion}

The acetalisation of glycerol with acetone was carried out over Amberlyst 15 as catalyst. The influence of various parameters such as reaction temperature, catalyst loading, acetone to glycerol molar ratio have been conducted to evaluate the glycerol conversion. It was observed that the Amberlyst 15 exhibit good performance as a solid catalyst which gave the highest glycerol conversion of $87.41 \%$. The acetone to glycerol molar ratio gave more influence to the glycerol conversion especially for the molar ratio of $2: 1$ to $3: 1$.

A kinetic model based on experimental data at of $35-60^{\circ} \mathrm{C}$ has been developed with PSSH approach as: $r_{\text {net }}=\frac{k_{4} \cdot C_{G} \cdot C_{A c}}{1+k_{5} \cdot C_{G}}$ with $\mathrm{k}_{4}$ and $\mathrm{k}_{5}$ were described as Arrhenius equations. From parameter estimation, preexponential factor of $0.04 \mathrm{~L}^{2} \cdot \mathrm{mol}^{-1} \cdot \mathrm{kg}^{-1} \cdot \mathrm{min}^{-1}$ and 0.81 were obtained for $\mathrm{A}_{4}$ and $\mathrm{A}_{5}$, respectively. The activation energy of $15.3 \mathrm{~kJ} / \mathrm{mol}$ and $26.8 \mathrm{~kJ} / \mathrm{mol}$ were obtained for $\mathrm{Ea}_{4}$ and $\mathrm{Ea}_{5}$, respectively. It appears that the model predicted the experimental data well at high conversion (above $80 \mathrm{~min}$ ) and showed relatively poor prediction below $80 \mathrm{~min}$.

The authors gratefully acknowledge the financial support provided by Ministry of Research, Technology and Higher Education, Republic of Indonesia under PDUPT grant of 2018, contract: 124/UN1/DITLIT/DIT-LIT/LT/2018.

\section{Notation}

$\mathrm{A}=$ pre exponential factor, mol L-1men-1

Ac $=$ acetone $\quad$, mol L-1

$\mathrm{Ea}=$ activation energy $\quad, \mathrm{J}$ mol-1

$\mathrm{G}=$ glycerol , mol L-1

$\mathrm{H}=$ hemi acetal , mol L-1

$\mathrm{k}=$ reaction rate constant , $\mathrm{L}$ mol-1L-1

$\mathrm{R}=$ gas constant $\quad, 8.314 \mathrm{~J}$ mol-1K

$\mathrm{S}=$ solketal , mol L-1

$\mathrm{T}=$ temperature, $\mathrm{K}$

* = catalyst surface active side

\section{References}

[1] Trifoi, A.R., Agachi, P.S. and Pap, T. Glycerol acetals and ketals as possible diesel additives. A review of their synthesis protocols. Renewable and Sustainable Energy Review, 62, 2016, 804813.

[2] Ilgen, O., Yerlikaya, S., Akyurek, F.O. Synthesis of solketal from glycerol and acetone over 
amberlyst-46 to produce an oxygenated. Periodica Polytechnica Chemical Engineering, 1, 2017, 1 - 5

[3] Dimistriev , G.S., Terekhov, A.V., Zanaveskin, L.N., Khadzhiev, S.N., Zanaveskin, K.L. and Maksinov, A.L. Choice of catalyst and technological scheme for synthesis of solketal. Russian Journal of Applied Chemistry. 89 (10), 2016, 1619 -1624.

[4] Reddy P.S., Sudarsanam, P., Mallesham B., Raju G., Reddy B.M. Acetalisation glycerol with acetone over zirconia and promoted zirconia catalysts under mild reaction conditions. Journal of Industrial and Engineering Chemistry, 17, 2011, 377.

[5] Malleshan, B., Rao, B.G. and Reddy, B.M. Production of biofuel additives by esterification and acetalization of bioglycerol. Comptes Rendus Chimic, 19, 2016, 1194 - 1202

[6] Manjunathan P., Maradur S.P., Halgeri A.B., Shanbag G.V. Room temperature synthesis of solketal from acetalization of glycerol with a acetone: Effect of crystallite size and the role of acidity of beta. Journal of Molecular Catalysis A: Chemical, 396, 2015, 47-54.

[7] Rossa V., Pessanha Y.S.P, Diaz G.C., Camara L.D.T., Pergher S.B.C., Aranda D.A.G. Reaction kinetic study of solketal production from glycerol ketalization with acetone, 56, 2017, 479 - 488

[8] Nanda M.R., Zhang Y., Qin W., Ghaziaskar H.S., Poirier M.A., Xu C.C. Thermodynamic and kinetic studies of a catalytic process to convert glycerol into solketal as an oxygenated fuel additive, Fuel, 117, 2014, 470-477.

[9] Shiirani, M., Ghaziaskar, H.S., Xu, C.C. Optimization of glycerol ketalization to produce solketal as biodiesel additive in a continuous reactor with supercritical acetone using Purolite PD 206 as catalyst. Fuel Processing Technology, 124, 2014, 206-2011.

[10] Samoilov, V.A., Ramazanov, D.N., Nekhaev, A.I., Maxinov, A.L., Bagdasarov, L.N. Heterogeneous catalytic conversion of glycerol to oxygenated fuel additives. Fuel, 172, 2016, 310-319.

[11] Esteban J., Ladero M., Garcia-Ochoa F., 2015, Kinetic Modelling for the Solventless Synthesis of Solketal with a Sulphonic Ion- Exchange Resin. .Chemical Engineering Journal, 269, 194

[12] Agirre, I., Garcia, I, Reqquies, J., Barrio, V.I., Guemez, M.B., Cambra, J.F. Glycerol acetals kinetics study of the reaction between glycerol and formaldehyde. Biomass Bioenergy. 35, 2011, 3636-3642.

[13] Khayoom M. S., Hameed, B. H., Soventless acetalization of Glycerol with acetone to fuel oxygenateds over $\mathrm{Ni}-\mathrm{Zr}$ supported on mesoporous activated carbon catalyst. Applied Catalysis A: General, 464-465, 2013, 191-199.

[14] Agirre, I., Gemez, M.B., Uguarte, A., Requies, J., Barrio, V.I., Cambra, J.F. Glycerol acetals as diesel additives: kinetics study of the reaction between glycerol and acetaldehyde. Fuel Processing Technology.116, 2013, 182-188.

[15] da Silva M.J., Rodrigues F.A., Julio A.A. SnF $_{2-}$ Catalyzed glycerol ketalization: A Friendly environmentally process to synthesize S3olketal at Room Temperature Over on Solid and Reuseable Lewis Acid, Chemical Engineering Journal, 307, 2017, 828. 